\title{
COMPARANDO A CULTURA ORGANIZACIONAL E A AUTOGESTÃO EM COOPERATIVAS DE RECICLAGEM DE SOROCABA E REGIÃO
}

\author{
COMPARING THE ORGANIZATIONAL CULTURE AND SELF-MANAGEMENT IN \\ RECYCLING COOPERATIVES IN SOROCABA AND SURROUNDINGS CITIES
}

\begin{abstract}
Resumo
O presente artigo analisa as práticas da autogestão nas cooperativas pertencentes à Rede Cata-Vida e à Central de Reciclagem de Sorocaba. A metodologia de coleta de dados envolveu a análise documental, a observação participante direta do trabalho e a realização de entrevistas com cooperados, parceiros e fundadores das cooperativas. $O$ estudo que analisou e comparou as diferentes culturas organizacionais dessas organizações revela que ambas estão preocupadas em educar os cooperados, visando à conscientização para a prática da autogestão das cooperativas. Porém, tais esforços de emancipação dos cooperados sofrem pressões do contexto social e econômico em que estão inseridos, enfrentando barreiras como a precária formação escolar dos cooperados, limitando muitas vezes a autogestão às decisões operacionais, enquanto as decisões estratégicas permanecem a cargo dos agentes externos.
\end{abstract}

Palavras-chave: Autogestão, cooperativas, cultura organizacional.

\begin{abstract}
This article analyzes the differences in the practice of self-management among cooperatives belonging to the Cata-Vida Network and the Sorocaba Recycling Center. The data collection methodology designed involves documental analysis, direct and participant observation of the work, and interviews with cooperative members, partners and founders. The study was carried out by comparing the organizational culture of the cooperatives belonging to the two organizations. The results revealed that both organizations are concerned with educating cooperative members so they are aware that they are owners and not employees, and thus they can effectively practice self-management at the cooperative. However, the efforts to emancipate cooperative members are hampered by the social and economic context in which they are embedded. Facing barriers such as precarious school education, self-management confines itself to operational decisions, while strategic decisions rely upon external agents' responsibility.
\end{abstract}

Keywords: Self-management, cooperatives, organizational culture.

Recebido: 17/04/2017 Aceito: 03/07/2017

Gabriel Machado Franco ${ }^{1}$, Tiago Fonseca Albuquerque Cavalcanti Sigahi ${ }^{2}$, Rodrigo dos Santos de Sousa ${ }^{3}$, Patrícia Saltorato ${ }^{4}$ ${ }^{1}$ Universidade Federal de São Carlos, campus Sorocaba - Rodovia João Leme dos Santos (SP-264), Km 110, Bairro do Itinga, Sorocaba, São Paulo, Brasil, CEP: 18052-780 - gabrielmachadofranco@gmail.com

${ }^{2}$ Universidade Federal de São Carlos, campus Sorocaba - Mestrando do Programa de Pós-Graduação em Engenharia de Produção tiago_sigahi@hotmail.com

${ }^{3}$ Universidade Federal de São Carlos, campus Sorocaba - Mestrando do Programa de Pós-Graduação em Engenharia de Produção rss.sousa@gmail.com

${ }^{4}$ Universidade Federal de São Carlos, campus Sorocaba - Docente do Programa de Pós-Graduação em Engenharia de Produção patriciasaltorato@gmail.com 


\section{Introdução}

O sistema capitalista apresenta uma organização do trabalho tipicamente heterogestionária que separa o trabalhador dos meios de produção e, consequentemente, separa também os atos de conceber e executar o trabalho.

Quando não participa da definição do seu trabalho, o trabalhador é colocado em uma posição passiva perante o seu papel na empresa e na sociedade. Com isso, a criticidade a respeito do seu futuro é desestimulada, fazendo com que métodos de trabalho denominados participativos deem lugar a sujeição e cooptação do trabalhador (BERNARDO, 2009; ANTUNES, 2014, p. 4).

Nas cooperativas a administração é autogestionária, uma vez que as decisões são tomadas de forma democrática nas assembleias gerais, onde cada cooperado representa um voto. O trabalho na cooperativa e a participação nas assembleias gerais elucidam o trabalhador sobre a influência que suas ações exercem na organização e, por conseguinte, na sua vida pessoal. Dessa forma, a empresa cooperativa cumpre o papel de guiar o trabalhador para uma educação social e libertadora.

No dia a dia do trabalho, os cooperados se deparam com problemas operacionais e administrativos que necessitam ser resolvidos por eles próprios. Esse processo de resolução de problemas envolve o esforço para se chegar a um consenso sobre o melhor plano de ação, além da superação de conflitos de interesse. Quando um trabalhador manifesta a sua opinião, ele não está somente aprendendo a criar e externar ideias, mas também está aprimorando sua capacidade de defendê-las a partir do seu ponto de vista.

Assim, a cooperativa revela-se como um espaço onde se ensina o trabalhador a agir socialmente e refletir criticamente sobre os problemas enfrentados, com vistas a uma educação libertadora e à desalienação do indivíduo.

Nesse contexto, o presente trabalho analisa as práticas da autogestão em duas organizações, cada qual com suas cooperativas filiadas e suas formas distintas de realizar o trabalho de coleta e separação, remunerar o cooperado e praticar a autogestão. Tais diferenças refletem em culturas organizacionais distintas que, por sua vez, transmitem diferentes valores aos cooperados em relação ao seu papel dentro da organização.
Assim, este artigo tem por finalidade analisar e comparar as culturas organizacionais dessas organizações, explorando-se sua influência nas práticas de autogestão realizadas pelos cooperados.

\section{Referencial teórico}

\section{$2.1 \mathrm{O}$ surgimento do cooperativismo}

No primeiro século da revolução industrial organizações chamadas trade clubs foram criadas pelos mestres de ofício com o intuito de capacitar os aprendizes em determinada profissão. Os trade clubs também tinham as funções de estabelecer um endereço para os mestres de ofício, instituir regras de ofício referentes ao número de profissionais e à base salarial, além de assegurar um fundo de pensão ao sócio que precisasse de auxílio enfermidade.

O avanço tecnológico, representado pelas invenções da fiação, da tecelagem e, posteriormente, da máquina à vapor, permitiu um grande aumento da produtividade e do volume de produção, o que acarretou na desvalorização de muitas profissões que passaram a ser realizadas com maior eficiência pelas máquinas. Esse avanço tecnológico impulsionou a organização dos trabalhadores qualificados em trade clubs, pois, desse modo, detinham o artifício da delimitação do número de trabalhadores de determinado ofício, permitindo que regulassem a oferta de mão de obra e aumentassem seu poder de barganha contra os empresários.

De acordo com Singer (1998, p. 90), a mais antiga cooperativa com existência documentada surgiu em 1760 a partir da iniciativa de trabalhadores de estaleiros localizados nas cidades de Woolwich e Chatham no Reino Unido. À época, trabalhadores que dependiam dos moinhos para processar seus cereais estavam sujeitos aos preços taxados pelos proprietários dos recursos. Em vista disso, tais trabalhadores fundaram moinhos de cereais em base cooperativa para não ter de pagar os altos preços cobrados pelos moleiros, que dispunham de um monopólio local (SINGER, 1998).

Ainda segundo o mesmo autor, em outras circunstâncias, fábricas que utilizavam quedas d'água como força motriz, instaladas em locais distantes da cidade, controlavam todos os estabelecimentos de moradia e venda de mantimentos próximos ao local de trabalho, fazendo com que os trabalhadores ficassem à mercê dos 
preços praticados pelas mesmas. Diante dessa situação, os trabalhadores formaram cooperativas de consumo, o que conferia a eles um maior poder de compra em escala, permitindo que negociassem os preços impostos pelos proprietários.

Tais experiências cooperativas, conforme Singer (1998, p. 94), embora socialistas em espírito, "no sentido de se considerarem pioneiras de uma sociedade melhor, que no futuro substituiria $o$ capitalismo", eram diferentes das comunidades cooperativas formadas por pessoas pertencentes à classe média e dependentes de contribuições filantrópicas para se estabelecer e até subsistir. Desse modo, o autor diferencia as cooperativas comunitárias - geralmente iniciativas de trabalhadores qualificados - das operárias, que surgem da luta de classe e constituem um genuíno movimento de massas, participando diretamente das lutas sindicais.

À mesma época, Robert Owen, um socialista utópico, difundia suas ideias sobre as "aldeias cooperativistas". Os fundos para a construção dessas aldeias começaram a ser capitalizados a partir da fundação dos equitable labour exchange, que podem ser entendidos como bazares de comércio onde eram realizadas trocas de mercadorias produzidas de forma autônoma ou por cooperativas. Tais mercadorias eram contabilizadas por horas de trabalho e pagas no momento em que eram depositadas na bolsa de intercâmbio de trabalho, sistema que facilitava o escoamento da produção. $\mathrm{O}$ fornecimento de crédito imediato aumentava o giro das mercadorias e "a avaliação em tempo de trabalho cumpria o que seria mais tarde codificado como um dos princípios do cooperativismo de consumo: a prática de preços justos" (SINGER, 1998).

Nesse período, Owen, que havia se tornado líder da militância sindical após os trabalhadores terem sido excluídos da reforma parlamentar, arquitetou um plano - batizado de Grand National Moral Union of the Productive Classes of the United Kingdom-, que viria a ser a primeira central sindical do mundo (OLIVEIRA; DELGADO, 2011, p. 176). No entanto, o plano de Owen foi recebido com hostilidade pela burguesia patronal, que reagiu demitindo funcionários, e esses, por sua vez, começaram a se filiar às cooperativas.

A disputa de poder entre sindicatos e patrões acarretou em lockouts gerais, deflagrados pelo patronato organizado, fazendo com que as cooperativas não conseguissem mais sustentar todos os afetados, encerrando o Grand National Moral Union de Owen, sucedido, posteriormente, pela Grand National Consolidated Trades Union (18331834) (OLIVEIRA; DELGADO, 2011, p. 177). A ofensiva contra o sindicato também enfraqueceu o giro de mercadorias da bolsa de intercâmbio de trabalhadores, que somado ao desequilíbrio das demandas das mercadorias por ela oferecidas, culminou no seu fim.

Em 1844, em Rochdale, surge a Society of Equitable Pioneers (FAIRBAIRN, 1999), uma cooperativa de consumo de operários têxteis, cuja fundação foi considerada um marco por apresentar um conjunto de princípios de cooperação que fornecem a base para o desenvolvimento de uma educação cooperativista (SINGER, 1998). Desde então, o movimento das cooperativas vivenciou acontecimentos importantes, entre os quais estão: a fundação da primeira cooperativa de produção industrial em 1850; a promulgação da lei das Sociedades Industriais e Cooperativas, em 1852, na Inglaterra, que passou a regular as relações das cooperativas com o Estado; a fundação da segunda cooperativa de produção em 1854; e, mais tarde, em Genebra, a criação, em 1895, da Aliança Cooperativa Internacional, que ratificou os princípios de Rochdale (LIMA, 2004, p. 46-47).

\subsection{Autogestão e cooperativismo}

As práticas cooperativistas foram originalmente organizadas em oito princípios, em 1844, pela cooperativa de Rochdale. Tais princípios foram atualizados e reorganizados por Gawlak (2007) em sete itens:

- $1^{\circ}$ princípio: adesão voluntária e livre;

- $2^{\circ}$ princípio: gestão democrática;

- $3^{\circ}$ princípio: participação econômica dos associados;

- $4^{\circ}$ princípio: autonomia e independência;

- $5^{\circ}$ princípio: educação, formação e informação;

- $6^{\circ}$ princípio: cooperação entre cooperativas;

- $7^{\circ}$ princípio: interesse pela comunidade.

Todo trabalhador associado a uma cooperativa é dono dos meios de produção. Logo, todos têm o mesmo direito acerca das decisões que permeiam os meios operacionais, táticos e estratégicos. Essa igualdade de poder sobre a gestão da empresa exige a autogestão, definida como o controle dos meios de 
produção e da gestão pelos trabalhadores (ANTEAG, 2000).

A principal prática da autogestão é a assembleia geral - órgão supremo da cooperativa -, que pode ser entendida como uma "reunião de todos os associados para, em conjunto, sugerir, discutir, analisar e tomar decisões sobre o desenvolvimento do empreendimento cooperativo" (GAWLAK, 2007, p. 61).

A autogestão, em tese, tem caráter emancipatório, pois, uma vez que o trabalhador é também o dono da empresa, ele deixa de ser um funcionário passivo em relação às estratégias da empresa e passa a ter poder de influência sobre o rumo do empreendimento. Na prática, porém, nem todos os cooperados julgam-se capacitados para tal ou ao menos têm vontade de participar das assembleias gerais. Ao abdicar dessa participação, os trabalhadores perdem mais do que a chance de exercer seu direito de escolha através do voto; perdem também a oportunidade de defender suas próprias ideias e tomar decisões, experiências que contribuem para sua educação e para torná-los pessoas mais confiantes (SINGER, 2002).

\subsection{Cultura organizacional}

Segundo Jones (2010), cultura organizacional é um conjunto de valores e normas compartilhados que regem as interações entre os membros da organização. Jones também reforça que a cultura organizacional pode ser utilizada para aumentar a eficácia organizacional, pois ela "controla a forma como os membros tomam decisões, a maneira como interpretam e administram o ambiente organizacional, o que fazem com as informações e como se comportam" (JONES, 2010, p. 147).

O estabelecimento de uma cultura organizacional ocorre através do ideal comum que os membros da organização têm sobre o modo de agir diante de uma situação. Esse modus operandi decorre do aprendizado obtido a partir de experiências passadas que foram exitosas e, por isso, assimiladas como pressupostos básicos. Assim, conforme Shein (1990), tais pressupostos são transmitidos aos novos membros como a forma correta de agir.

A análise da cultura organizacional não é uma tarefa simples, pois, enquanto para os membros da organização tomar determinadas decisões pode parecer óbvio - em alguns casos de forma até mesmo inconsciente -, para o analista as ações podem aparentar não ter explicação racional, podendo passar despercebidas.

Baseada nos estudos de Shein (1999), Fleury (2007) desenvolveu uma proposta metodológica para analisar a cultura organizacional. A autora defende que o estudo da cultura organizacional deve ser realizado a partir da análise das seguintes perspectivas: histórico da organização; processo de socialização de novos membros; políticas de recursos humanos; processo de comunicação; e organização do processo de trabalho.

A investigação sobre a origem da organização contribui para o entendimento sobre os valores que os funcionários carregam consigo, uma vez que os fundadores têm grande influência sobre a concepção desses valores. Dessa maneira, a entrevista com o fundador da organização objeto de estudo é imprescindível para a análise da cultura da mesma. Durante o processo de investigação histórica, é de grande importância a análise dos incidentes críticos - pontos de inflexão de fracasso ou sucesso - vividos pela organização, pois são nesses momentos "que certos valores importantes de serem preservados ou pelo contrário, questionados, emergem com maior nitidez" (FLEURY, 2007, p. 23).

A autora defende que é através do processo de socialização que tais valores são transmitidos e incorporados. A socialização habitualmente ocorre através dos programas de treinamento e integração de novos membros, onde são explicitados, na concepão da empresa, quais valores devem ser praticados e quais atitudes são erradas.

A forma como se dá a relação entre o capital e o trabalho pode explicar como os valores da organização são formados. Nesse sentido, Fleury (2007, p. 24) destaca a importância de se investigar as políticas de recursos humanos explíticas (e.g. recrutamento, seleção, treinamento, remuneração) e implícitas, pois a observação de consistências ou inconsistências ajuda a decifrar os padrões culturais da organização.

Quanto aos processos de comunicação, segundo Fleury (2007, p. 24), esses constituem elementos essenciais no processo de criação, transmissão e cristalização do universo simbólico de uma organização. É preciso analisar tanto os meios formais (e.g. reuniões, jornais, circulares) quanto os informais, contribuindo para um melhor 
entendimento das relações entre categorias, grupos e áreas organizacionais (FLEURY, 2007, p. 24).

Por fim, ainda é necessário estudar os componentes tecnológicos e sociais da organização do processo de trabalho. De acordo com Fleury (2007), tal análise possibilita: a identificação das categorias presentes na relação de trabalho; o mapeamento das relações de poder entre categorias e áreas da organização; e desvendar aspectos formadores da identidade organizacional. Além disso, o estudo da organização do processo de trabalho é importante para entender como os elementos simbólicos da cultura organizacional instrumentalizam as relações de poder (FLEURY, 2007, p. 25).

\subsection{Coleta seletiva}

O sistema de coleta seletiva está sustentado no potencial de reciclagem de materiais como papel, papelão, plástico e metal (BARTHOLOMEU; CAIXETA-FILHO, 2011), provenientes de diferenes fontes geradoras (e.g. residências, empresas, escolas, comércio, indústrias), tendo em vista a coleta e o encaminhamento para a reciclagem. Esses materiais representam cerca de $30 \%$ da composição do lixo domiciliar brasileiro, que na sua maior parte é composto por matéria orgânica (DEMAJOROVIC; LIMA, 2013, p. 51).

Segundo Ribeiro e Besen (2007, p. 4), a separação dos materiais recicláveis cumpre um papel estratégico na gestão integrada de resíduos sólidos sob vários aspectos: estimula o hábito da separação do lixo na fonte geradora; promove a educação ambiental, alertando sobre a redução do consumo e do desperdício; gera trabalho e renda; entre outros. Além disso, O’Leary e Walsh (1999) observam que a reciclagem é uma alternativa viável para propiciar a preservação de recursos naturais, a economia de energia, a redução da área que demanda o aterro sanitário, bem como a conscientização da população para questões ambientais.

Dessa forma, as cooperativas de reciclagem cumprem o papel de difusoras da educação ambiental dentro da própria organização, pois conscientizam seus funcionários de que a separação adequada agrega valor ao material que seria jogado no lixo; e na comunidade à sua volta, uma vez que o trabalho realizado pela cooperativa estimula os moradores a se engajarem na separação dos materiais em seus estabelecimentos.

Além dos catadores (autônomos ou cooperados) e das indústrias (recicladoras ou de transformação) que compram o material reciclado, é importante notar a atuação dos compradores intermediários, também chamados de atravessadores ou sucateiros, que exploram o trabalho dos catadores (VENANZI et al., 2015). O domínio dos atravessadores sobre a comercialização dos materiais recicláveis revela um baixo índice de organização dos catadores na tentativa de negociar diretamente com as indústrias, o que gera como consequência um menor retorno financeiro sobre o material coletado.

\subsubsection{Coleta seletiva em Sorocaba e região}

De acordo com o Panorama dos Resíduos Sólidos no Brasil (ABRELPE, 2011), Sorocaba coletou em 2011 uma média de 530 toneladas de resíduos sólidos urbanos por dia. A coleta seletiva em Sorocaba e região é realizada por meio de um programa incentivado e apoiado pelas prefeituras que direcionam esforços conjuntos para dar destino adequado ao lixo gerado.

A coleta na cidade de Sorocaba é realizada por quatro cooperativas que atendem diferentes regiões conforme divisão estabelecida pelo poder público municipal: Reviver (Nordeste); Catares (Centro e Sul); Ecoeso (Noroeste) e Coreso (Oeste, Leste e Norte).

A gestão do programa de coleta em Sorocaba e região é realizada pela Central de Reciclagem de Sorocaba (ou Central de Reciclagem da Zona Oeste) e pela Rede Cata-Vida. A primeira processa a catação das cooperativas Reviver, Catares e Ecoeso, enquanto a segunda gerencia a coleta da Coreso e de outras 16 cooperativas, cada qual atuando em um município localizado nos arredores da cidade de Sorocaba.

\section{Metodologia}

O presente trabalho consiste em um estudo comparativo que investiga a influência da cultura organizacional nas práticas de autogestão de duas organizações que possuem cooperativas filiadas. Inicialmente, foi realizada uma revisão da literatura que aborda os seguintes temas: conceito, origem e 
evolução do cooperativismo; autogestão como ferramenta para a emancipação do trabalhador; cultura organizacional e modelos analíticos; e coleta seletiva.

Foi utilizada também a pesquisa documental para a identificação de aspectos relacionados ao funcionamento e à atuação das cooperativas filiadas às organizações estudadas (Central de Reciclagem de Sorocaba e Rede Cata Vida).

A metodologia de coleta de dados envolveu a análise de documentos (jornal das cooperativas, jornal das prefeituras, jornais e site do CEADEC Centro de Estudos e Apoio ao Desenvolvimento, Emprego e Cidadania), entrevistas com membros, parceiros e fundadores das cooperativas, além de observação direta do trabalho dos cooperados.

Optou-se pela realização de entrevistas não estruturadas para que houvesse maior flexibilidade em sua condução, abordando-se os assuntos de maior interesse. De acordo com Gil (1999), ainda que a entrevista não seja estruturada, esta deverá ter uma pauta. Assim, foram definidos previamente tópicos a serem abordados durante a entrevista, cabendo ao entrevistador identificar o(s) momento(s) mais propício(s) para tal.

As entrevistas tiveram como objetivo a coleta de informações referentes às perspectivas propostas por Fleury (2007): histórico da organização; processo de socialização de novos membros; políticas de recursos humanos; processo de comunicação; e organização do processo de trabalho.

As análises dos jornais das cooperativas e do site do CEADEC também auxiliaram na compreensão do processo de comunicação formal, além de conterem informações referentes à história das organizações e aos incidentes críticos vivenciados por elas. Ademais, o método de observação direta do trabalho dos cooperados permitiu coletar informações acerca dos processos informais de comunicação e da maneira como se dá a organização do processo de trabalho.

\section{Análise da cultura organizacional: Rede Cata-Vida}

\subsection{Histórico da organização}

Em 1999, no município de Sorocaba, o CEADEC, em parceria com uma instituição religiosa, fundou a Cooperativa de Reciclagem da Zona Norte de Sorocaba.

Nos anos seguintes, com o intuito de promover e ampliar a organização da coleta seletiva, o CEADEC ajudou a fundar também a Coreso (Cooperativa de Reciclagem de Sorocaba), a Coopervot (Cooperativa de Reciclagem de Votorantim), a Acamar (Associação dos Catadores de Materiais Recicláveis) e a Coresp (Cooperativa de Reciclagem de Salto de Pirapora).

Tais cooperativas, apesar de terem sido criadas a partir de uma mesma organização - o CEADEC -, atuavam de forma isolada, resultando em um baixo volume de coleta de material reciclável, o que impossibilitava a comercialização direta com as indústrias, elevando-se o poder de barganha dos atravessadores. Essa situação, porém, segundo informações da Rede Cata-Vida, mudou no ano de 2001 quando ocorreu o Encontro Regional das Cooperativas promovido pelo CEADEC.

O evento impulsionou ações das cooperativas, juntamente com a Coordenação Regional dos Catadores, tornando possível a implantação da logística integrada das cooperativas. A partir de então, as instalações da Coreso foram transformadas na Central de Triagem e Comercialização da Rede Solidária Cata-Vida (Rede Cata-Vida), passando a receber e acondicionar $o$ material a ser comercializado.

\subsection{O processo de socialização de novos membros}

O processo de socialização do cooperado da Rede Cata-Vida se inicia com o contato entre antigos e novos membros, com o objetivo de que os primeiros esclareçam aos segundos "o que é uma cooperativa".

Esse contato é realizado geralmente no próprio local de trabalho (galpão de separação), frisando-se ideias como a de que "o cooperado é o próprio dono do seu trabalho" e que, portanto, "tem o direito de fazer parte das decisões da empresa"; porém, alertando-os também do fato de que os membros da cooperativa não usufruem dos benefícios que a CLT prevê para um assalariado.

O início do trabalho do novo membro conta com o acompanhamento de um cooperado mais experiente. Nessa fase, é transmitida ao novato a ideia de que todo o material que ele tem para separar 
representa a sua renda no final do mês, reforçandose o quão é importante que ele não despreze nenhum material.

As cooperativas que compõem a Rede CataVida se diferenciam quanto à divisão dos lucros: a maior parte delas distribui o lucro de forma igualitária entre todos os membros, enquanto as demais pagam os cooperados de acordo com o que cada um produz. Essa característica de diferenciação da forma de divisão dos lucros influencia na socialização dos novos membros. As cooperativas que adotam o modelo de divisão igualitária se preocupam mais em conscientizar o novo integrante que a eficiência do seu trabalho interfere diretamente na renda de todos os membros, enquanto o modelo baseado na produtividade remete a comportamentos individuais e competitivos.

O processo de socialização inclui ainda a realização de cursos que abordam o funcionamento da Rede Cata-Vida e a maneira como a mesma articula todas as cooperativas, além de tratar de questões como "o que é cooperativismo?". Esses cursos são realizados sempre que houver um grupo de aproximadamente dez novos membros.

\subsection{As políticas de recursos humanos}

A Rede Cata-Vida é uma cooperativa de segundo grau que reúne todo o material coletado e separado pelas cooperativas filiadas para comercializá-los diretamente com as indústrias recicladoras.

$\mathrm{Na}$ Central de Triagem e Comercialização são realizados os processos de armazenamento, pesagem e aferição do valor que deve ser pago para cada cooperativa de acordo com a sua produção. Esse valor é calculado com base no preço do quilo do material no mês correspondente, uma vez que o preço de cada material é dinâmico e varia de acordo com os níveis de oferta e demanda do material.

No caso das cooperativas que adotam o modelo de divisão igualitária de lucros, ocorre um maior controle dos membros por eles próprios quanto a aspectos como faltas no trabalho, habilidade no manuseio do material, velocidade na separação e paradas para necessidades de descanso ou até mesmo fisiológicas.

A alta incidência de discussões relacionadas a tais aspectos levou algumas cooperativas, como a Cotmap (Cooperativa de Piedade) e um dos núcleos da Coreso, a reformularem seu sistema de remuneração: os cooperados passaram a ser remunerados de acordo com a sua produção na etapa de separação do material. Dessa maneira, houve a necessidade de adaptação por parte dos cooperados da maneira como era realizado o trabalho, pois cada membro deveria separar em um recipiente chamado de bag - o material coletado na rua, pois este serviria de base para o cálculo da sua remuneração.

Outras mudanças no trabalho foram necessárias, relacionadas aos membros que exerciam funções específicas na cooperativa, a saber: controle da prensa e condução do veículo de coleta. Devido às suas ocupações, tais membros não exerciam a atividade específica de coleta do material, sendo sua remuneração determinada com base no material proveniente de doações.

Vale ainda destacar a relação entre a Rede Cata-Vida e o CEADEC. Cada membro pertencente a uma das cooperativas filiadas à Rede Cata-Vida deve contribuir com $15 \%$ da sua renda para um fundo cooperativo destinado à capacitação dos cooperados, que fica a cargo do CEADEC. Esse fundo também é utilizado na remuneração de quatro cooperados que possuem funções distintas: um encarregado administrativo e três responsáveis pela "disseminação dos valores e estratégias" nas cooperativas filiadas à Rede Cata-Vida, sendo que um destes acumula o cargo de tesoureiro.

No período em que o presente trabalho foi realizado, os cooperados da Cooperativa de Reciclagem de Sorocaba (Coreso), filiada à Rede Cata-Vida, que tinham sua remuneração baseada na produção, ganhavam mensalmente entre $\mathrm{R} \$ 700,00 \mathrm{e}$ $\mathrm{R} \$ 1.200,00$. Já aqueles com funções diferenciadas recebiam uma compensação financeira de cerca de $\mathrm{R} \$ 1.500,00$.

\subsection{O processo de comunicação}

Todas as cooperativas da Rede Cata-Vida seguem determinados padrões: o uso da mesma indumentária por todos os cooperados; o uso de caminhões como veículo de coleta; e o uso de bancadas para separação do material. Essa uniformidade e padronização foram alcançadas devido à atuação e capacitação realizada pelo CEADEC. 
Mensalmente, representantes de cada cooperativa realizam uma reunião, mediada pelo CEADEC, onde ocorre a atualização das metas estratégicas definidas pela Rede Cata-Vida. Tais metas são definidas pelo próprio CEADEC, que acumula ainda a responsabilidade pela captação de recursos provenientes de projetos de empresas privadas ou instituições públicas.

No período de realização do estudo, o CEADEC realizava investidas para estabelecer relações entre a Rede Cata-Vida (Sorocaba e região), a Rede Cata-Sampa (São Paulo) e a Cata-Bahia (Bahia), visando à transformação do material coletado em produtos com maior valor agregado, sendo que cada cooperativa teria como foco um tipo de material, somando-se os volumes obtidos por essas cooperativas. Apesar de possuir um triturador de polímeros e uma extrusora, a Rede Cata-Vida não conseguia utilizar este maquinário (produção de canos de plástico) devido ao baixo volume coletado desse material. Assim, através desta comunicação inter-redes, espera-se obter material suficiente reunindo-se as coletas das cooperativas filiadas às três organizações.

Em relação aos processos de comunicação entre as cooperativas da Rede Cata-Vida e o CEADEC, uma das entrevistadas, funcionária desse último, salientou que as cooperativas possuem autonomia quanto às decisões operacionais, sendo que a tomada de decisão é sempre realizada em assembleia geral. Por outro lado, as decisões estratégicas têm caráter top-down, uma vez que o CEADEC possui poder de decisão sobre quais projetos serão realizados, cabendo aos cooperados somente participar das reuniões para serem informados do futuro da Rede Cata-Vida.

\subsection{Organização do processo de trabalho}

A coleta de materiais recicláveis nas residências constitui a primeira etapa do processo de trabalho das cooperativas. Uma das funcionárias do CEADEC entrevistada nesse estudo observou que a coleta porta a porta possui um papel importante de conscientização do morador sobre o trabalho ambiental e social que a cooperativa realiza.

O contato entre o cooperado e o morador, além de dar voz ao agente ambiental (catador), também favorece a fidelização do morador, o que significa que ele passa a confiar que o material será coletado semanalmente, evitando que se acumule uma grande quantidade em sua residência.

Inicialmente, as cooperativas forneciam sacolas para que os moradores guardassem o material, prática que foi encerrada, pois, segundo o CEADEC, estimulava os moradores a contribuírem somente quando recebiam a sacola, além de gerar mais resíduos a partir da compra das sacolas.

O material é coletado com o auxílio de caminhões fornecidos pela prefeitura e é levado para os galpões das cooperativas, onde são encaminhados às etapas seguintes de separação e, posteriormente, prensagem.

$\mathrm{Na}$ etapa de separação, identificou-se uma diferença decorrente do sistema de remuneração diferenciado das cooperativas. Nas cooperativas em que a divisão do lucro é igualitária, três cooperados trabalham em cada bancada de separação, havendo a supervisão de uns pelos outros. Por sua vez, aquelas que remuneram por produção, posicionam um cooperado por bancada.

A separação é realizada pelo transbordamento das bags coletadas pelos caminhões nas mesas de separação e posterior separação em bags específicas. O material, então, segue para a etapa de prensagem, responsabilidade de um cooperado especializado nesse tipo de processo. Nas cooperativas em que a remuneração é baseada na produtividade individual, este profissional recebe um salário calculado como a média da renda de todos os cooperados.

O material presando, agora em formato de fardo, é levado até a Central de Reciclagem e Comercialização da Rede, onde são realizadas as etapas de pesagem e precificação de acordo com a lista dinâmica de preço dos materiais. Descontandose $15 \%$ do valor da venda destinado ao fundo cooperativo citado anteriormente, o valor resultante é convertido às cooperativas.

\section{Análise da cultura organizacional: Central de Reciclagem de Sorocaba}

\subsection{Histórico da organização}

A Central de Reciclagem de Sorocaba é responsável por gerir as atividades das cooperativas Catares, Reviver e Ecoeso.

A Ecoeso foi originada a partir da criação da Coeso (Centro de Orientação e Educação Social), organização não-governamental que buscava a 
proteção de crianças carentes vulneráveis ao tráfico de drogas e à exploração sexual.

$\mathrm{O}$ desenvolvimento do trabalho junto a estas crianças fez com que os funcionários da ONG percebessem a necessidade de se trabalhar não só no desenvolvimento da criança, mas sim de toda a estrutura familiar à sua volta. Assim, com o intuito de oferecer uma opção de renda para as famílias assistidas, foi criada a cooperativa IESA (Instituto de Educação Sócio Ambiental) em 16 de maio de 2007, que produzia sabão ecológico a partir do óleo vegetal usado.

Pouco tempo depois, em 5 de julho de 2007, a Coeso, em parceria com a prefeitura de Sorocaba, que cedeu o espaço para as instalações, criou a Ecoeso (Cooperativa de Empoderamento Social), com o objetivo de organizar o trabalho de catadores independentes para que houvesse volume suficiente de material para comercialização direta com as indústrias.

O sistema de remuneração dessa cooperativa era baseado em uma renda mensal fixa igual a todos os catadores. Ao final do período de um ano, todos recebiam uma quantia equivalente à divisão igualitária do excedente do lucro.

Em 2011, quando foi inaugurada a Central de Reciclagem de Sorocaba, a Ecoeso foi incorporada pela Catares e Reviver.

A Reviver - inicialmente denominada Núcleo de Reciclagem de Sorocaba - surgiu em 2004, a partir da iniciativa conjunta de uma instituição religiosa local, do CEADEC, e da Coreso (filiada à Rede Cata-Vida). Em 2007, a Reviver se emancipou da Rede Cata-Vida tornando-se uma cooperativa independente.

Por sua vez, a Cooperativa de Trabalho dos Catadores de Material Reaproveitável de Sorocaba (Catares), criada em 22 de maio de 2004, teve como mantenedora a Universidade de Sorocaba (Uniso), que contou com o apoio da prefeitura municipal.

Atualmente, as cooperativas Catares e Reviver trabalham juntas em um mesmo galpão conhecido como Central de Reciclagem de Sorocaba, organização responsável pela administração financeira de ambas.

\subsection{O processo de socialização de novos membros}

A socialização de novos membros ocorre basicamente por meio de treinamentos sobre o que são, na concepção da organização, cooperativas e sistemas cooperativistas.

Nos treinamentos são explicitadas as diferenças que existem entre os trabalhadores de empresas capitalistas e de cooperativas. São destacados pontos importantes relacionados ao valor da coletividade, como a necessidade de se adequar ao sistema de trabalho em grupo e da gestão democrática que é prevista em lei, no estatuto e regulamento interno da cooperativa.

Outras ideias, regras e valores bastante difundidos são: os novos membros associados se tornam donos da cooperativa através de aquisição de quotas; a cooperativa possui um limite máximo de sócios conforme estatuto e legislação; a CLT não se aplica ao trabalho do cooperado; os rendimentos são variáveis dependendo do lucro apurado ao fim do período (mensal); organizados em assembleias, os cooperados têm autonomia para democraticamente estabelecerem as regras de destinação dos lucros e de seus investimentos; deve ser praticada a valorização do trabalho do "agente ambiental", evitando-se termos comumente usados de forma pejorativa como "catadores de lixo", "catadores de reciclados", "lixeiros", "catadores de rua", "carrilheiros", etc; conscientização da atividade cooperativista como meio de transformação e valorização humana; respeito às horas de descanso permitidas para relaxar e recuperar energia; ter postura de "dono" e, desse modo, ter especial atenção com a eficiência de toda a operação.

\subsection{As políticas de recursos humanos}

O papel de intervenção da administração pública, que oferece em comodato os equipamentos e aloca instalações, evita que as cooperativas tenham que arcar com as despesas e o custeio de manutenção dos equipamentos. Por outro lado, tal situação faz com que investimentos em maquinário com vistas a melhorar a produtividade tenham que partir da iniciativa da prefeitura, e não dos proprietários da organização, isto é, dos cooperados.

As cooperativas da Central de Reciclagem de Sorocaba adotam um modelo igualitário de remuneração baseado no número de horas trabalhadas, não havendo distinção entre as tarefas exercidas pelos cooperados. São descontados de 
cada associado: 5\% de taxas de limpeza; $11 \%$ referente ao INSS; $2 \%$ para o pagamento da quotaparte até a quantia acumulada de $\mathrm{R} \$ 300,00$, valor que é devolvido em caso de desligamento da cooperativa; e 3,65\% destinado aos impostos PIS e COFINS.

Ainda que não haja nenhuma distinção salarial, é possível ascender dentro da organização, por exemplo: tornar-se líder de equipe, exercendo atividades de delegação e controle de atividades de outros cooperados; ser realocado para o escritório, trabalhando na parte administrativa da cooperativa; e até mesmo ser transferido para outras empresas ou ONGs, como reconhecimento por um eventual trabalho de destaque prestado na cooperativa.

Embora seja de conhecimento de todos a existência de tais possibilidades de ascensão, as cooperativas apresentam alta rotatividade, visto que muitos dos cooperados encaram a coleta seletiva como um serviço temporário - o que explica a insistência das cooperativas em reforçar a ideia de "postura de dono". Assim, a maioria dos cooperados prefere ser administrado, fazendo com que decisões estratégicas fiquem a cargo de outras instituições (sem fins lucrativos, ONGs, etc). Tais decisões afetam diretamente o cooperado e envolvem, por exemplo, mudanças de layout, proposição de novas formas de organizar o trabalho, investimento em novos equipamentos e em automatização de processos, entre outras.

Quanto às políticas de desenvolvimento, são disponibilizadas capacitações (e.g. recursos humanos, segurança do trabalho) e assistências (e.g. social, psicológica, terapia ocupacional), oferecidas por diversas instituições e empresas da região, dentre elas o SENAC (Serviço Nacional de Aprendizagem Comercial), o SEBRAE (Serviço Brasileiro de Apoio às Micro e Pequenas Empresas), a Uniso (Universidade de Sorocaba), entre outras.

\section{$5.4 \mathrm{O}$ processo de comunicação}

Cientes da baixa escolaridade dos membros das cooperativas, a linguagem utilizada nos processos de comunicação emprega vocabulário simples e de fácil compreensão. Geralmente, poucos são os avisos dispostos nos murais devido à dificuldade de leitura que possui a maioria dos cooperados. Dessa maneira, a comunicação é feita predominantemente de maneira direta, informal e verbal.

Nesse cenário, o setor de Comunicação Social direciona esforços para alertar a opinião pública não só acerca do papel ambiental exercido pelas cooperativas, mas também sobre o benefício social decorrente de suas atividades. De acordo com os entrevistados, muitos foram os cooperados que vieram de situações de dependência química e, na grande maioria das vezes, de ambientes familiares desestruturados.

Observou-se também a prática dos cooperados de elegerem um líder do grupo que passa a ser o porta-voz no tratamento de assuntos mais complexos. Percebeu-se, claramente, que apesar de haver treinamentos e palestras sobre o tema, o conhecimento sobre a legislação pertinente era praticamente nulo entre os cooperados.

\subsection{Organização do processo de trabalho}

A composição do quadro de cooperados dessa organização revela que a razão entre o número de mulheres e o número de homens é igual a nove. Segundo um dos entrevistados, a predominância do gênero feminino entre os cooperados pode ser explicada pela preferência de grande parte dos homens em trabalhar como catadores independentes realizando a venda do material coletado para atravessadores.

Apesar de muitos catadores preterirem a opção de se associarem às cooperativas, a Central de Reciclagem de Sorocaba coletou e comercializou, em 2012, 2.400 toneladas de material, o que corresponde a $3.200 \mathrm{~kg} / \mathrm{mês}$ por associado, tendo uma remuneração mensal média de $\mathrm{R} \$ 1.200,00$. Além disso, contam com profissionais experientes encarregados da gestão das cooperativas, que inclusive aplicam técnicas de redução de desperdícios de material, tempo e movimentação, somadas ao uso de recursos como esteiras motorizadas e bancadas desenvolvidas especialmente para o processo de separação.

\section{Conclusão}

Ambas as organizações estudadas - Rede Cata-Vida e Central de Reciclagem de Sorocaba presentaram preocupação em desenvolver no cooperado o senso de coletivo, cientes de que o 
sucesso das cooperativas está intimamente ligado à dedicação de cada um dos trabalhadores. Mesmo no caso das cooperativas da Rede Cata-Vida que adotam um modelo de remuneração baseado na produtividade individual, e, portanto, acirram a disputa entre cooperados, não deixam de praticar a coletividade em seus processos. Apesar do fato de o trabalho de separação do material ser realizado individualmente (cada cooperado possui sua própria mesa), a coleta de porta a porta é coletiva e as assembleias gerais representam um espaço de validação da autogestão. Além disso, embora a remuneração seja proporcional à produção individual, a resolução de problemas operacionais é praticada visando o interesse de todos.

A Rede Cata-Vida e a Central de Reciclagem de Sorocaba se assemelham no empenho da transmissão ao cooperado do "pensamento de dono". Embora esse valor remeta às ideias de empoderamento, emancipação e desalienação do trabalhador, muitos ainda carregam consigo a visão capitalista proveniente de experiências passadas, e preferem os riscos de continuar trabalhando de forma autônoma para "se manterem independentes", comercializando o pouco material coletado com atravessadores. Outra barreira para que ocorra essa transformação do catador em "dono" da cooperativa é a baixa instrução dos mesmos, o que dificulta sua formação crítica.

A pouca participação dos cooperados nas decisões estratégicas é similar em ambas as organizações. A baixa escolaridade também exerce aqui um papel limitador da atuação dos cooperados, uma vez que estes detêm apenas conhecimento referente às atividades operacionais, o que faz com que não se sintam qualificados o bastante para assumir responsabilidades sobre $\mathrm{o}$ futuro $\mathrm{da}$ organização como um todo, e, consequentemente, deles próprios.

A Rede Cata-Vida se mostrou um espaço mais favorável aos cooperados em termos de decisão sobre o seu próprio sistema de remuneração. Mostra disso são as distintas formas de divisão do lucro existentes em cooperativas pertencentes à mesma organização.

As cooperativas Catares e Reviver, que compõem a Central de Reciclagem de Sorocaba, possuem uma grande barreira em relação à autonomia de mudança da organização dos processos de trabalho, uma vez que dividem o mesmo espaço físico e os mesmos recursos. Por outro lado, mostraram ser mais eficazes, sendo que a remuneração média é de $\mathrm{R} \$ 1.200,00$, enquanto o mesmo valor corresponde à remuneração máxima da Rede Cata-Vida. Além disso, o uso de técnicas e recursos mais avançados permitem a redução de desperdícios e da carga de trabalho físico a que são submetidos os cooperados.

As esteiras mecanizadas de separação da Central de Reciclagem de Sorocaba aludem ao sistema fordista de produção. Contudo, a cooperativa permite que os cooperados realizem o job rotation (troca de posto de coleta), fazendo com que varie o material a ser coletado e a atividade realizada. Além disso, os cooperados contam com períodos de descanso que visam à diminuição das cargas de trabalho física e cognitiva.

Nas cooperativas da Rede Cata-Vida, a distribuição de bancadas de separação remete às células de produção do sistema toyotista, sendo que os cooperados de cada bancada são responsáveis pela separação de todos os tipos de materiais, refletindo em uma maior variabilidade da tarefa. Em contrapartida, essa forma de organizar o trabalho é desfavorável à limpeza do ambiente, pois exige uma maior movimentação das bags, o que resulta em uma maior quantidade de resíduo na mesa de separação e no solo. Além disso, a Rede Cata-Vida apresenta equipamentos mais antigos e um menor nível de automatização de sua produção, o que pode explicar a menor produtividade em relação à Central de Reciclagem de Sorocaba.

Observou-se que a Central de Reciclagem de Sorocaba favorece o processo de socialização entre os cooperados ao posicioná-los todos em uma mesma bancada de separação, permitindo que conversem enquanto trabalham. De outro modo, a Rede Cata-Vida limita em no máximo três cooperados por bancada, sendo esse processo individual nas cooperativas em que o sistema de remuneração é baseado no que cada cooperado produz.

Em diversos aspectos, ambas as organizações estudadas trabalham no sentido de desenvolver seus cooperados, embora muitas das tentativas esbarrem em fatores socioculturais e econômicos de difícil resolução. Ainda assim, observou-se variadas medidas de combate à precarização do trabalho e à alienação do trabalhador, fazendo com que antigos catadores, que antes trabalhavam na rua em péssimas 
condições físicas e cognitivas, hoje façam parte de uma cooperativa que fornece certa estabilidade econômica e oportunidades de uma educação social e libertadora.

\section{Referências}

ABRELPE - ASSOCIAÇÃO BRASILEIRA DE EMPRESAS DE LIMPEZA PÚBLICA E RESÍDUOS ESPECIAIS. Panorama dos Resíduos Sólidos no Brasil, 2011. Disponível em <http://www.abrelpe.org.br/Panorama/panorama 2011.pdf > Acesso em 13 abr. 2017.

\section{ANTEAG - ASSOCIAÇÃO NACIONAL DOS} TRABALHADORES EM EMPRESAS DE AUTOGESTÃO. Autogestão: construindo uma nova cultura de relações de trabalho. São Paulo: ANTEAG, 2000.

ANTUNES, R. A nova morfologia do trabalho e as formas diferenciadas da reestruturação produtiva no Brasil dos anos 1990. Sociologia: Revista da Faculdade de Letras da Universidade do Porto, v. 27, p. 11-25, 2014.

BARTHOLOMEU, D.B.; CAIXEITA-FILHO, J.V. Logística ambiental de resíduos sólidos. São Paulo: Atlas, 2011.

BERNARDO, M.H. Flexibilização do discurso de gestão como estratégia para legitimar o poder empresarial na era do toyotismo: uma discussão a partir da vivência de trabalhadores. Cadernos de Psicologia Social do Trabalho, v. 12, n. 1, p. 93109, 2009.

DEMAJOROVIC, J.; LIMA, M. Cadeia de Reciclagem: um olhar para os catadores. São Paulo: SENAC, 2013.

FAIRBAIRN, Brett. The meaning of Rochdale: the Rochdale pioneers and the co-operative principles. Saskatoon: University of Saskatchewan, Centre for the Study of Cooperatives, $1994.70 \mathrm{p}$.

FLEURY, M.T.L. O desvendar a cultura de uma organização: uma discussão metodológica. In: FLEURY, M.T.L.; FISCHER, R.M. (orgs.).
Cultura e poder nas organizações. São Paulo: Atlas, 2007.

GAWLAK, A. Cooperativismo: primeiras lições. Brasília: Sescoop, 2007.

GIL, A.C. Métodos e técnicas de pesquisa social ( $5^{\mathrm{a}}$ ed.). São Paulo: Atlas, 1999.

JONES, G.R. Teoria das organizações ( $6^{\mathrm{a}}$ ed.). São Paulo: Pearson Education to Brasil, 2010.

LIMA, J.C. O trabalho autogestionário em cooperativas de produção: o paradigma revisitado. Revista Brasileira de Ciências Sociais, v. 19, n. 56, p. $45-62,2000$.

O'LEARY, P.R.; WALSH, P.W. Decision maker's guide to solid waste management $\left(2^{\mathrm{a}} \mathrm{ed}.\right)$. Washington: U.S. Environmental Protection Agency, 1999. 372 p.

OLIVEIRA, B.A.; DELGADO, N.G. A economia solidária: variantes e alguns suportes constitutivos. Gerais: Revista Interinstitucional de Psicologia, v. 4, p. 173-185, 2011.

RIBEIRO, H; BESEN, G.R. Panorama da Coleta Seletiva no Brasil: Desafios e Perspectivas a partir de Três Estudos de Caso. INTERFACEHS: Revista de Gestão Integrada em Saúde do Trabalho e Meio Ambiente, v. 2, n. 4, p. 1-18, 2007.

SHEIN, E.H. Organizational Culture. American Psychologist, v. 45, n. 2, p. 109-119, 1990.

SINGER, P. Uma utopia militante: repensando o socialismo (2 $2^{\mathrm{a}}$ ed.). Petrópolis, RJ: Vozes, 1998.

SINGER, P. Introdução à Economia Solidária. 6. Ed. São Paulo, SP: Fundação Perseu Abramo, 2002.

VENANZI, D.; MARTOS, H.; DA SILVA, O.R.. Estudo do processo de operação de reciclagem de resíduos provenientes da coleta seletiva de lixo no município de Itu/SP. REMIPE: Revista de Micro e Pequenas Empresas e Empreendedorismo da Fatec-Osasco, v. 1, n. 1, p. 95-108, 2015. 
